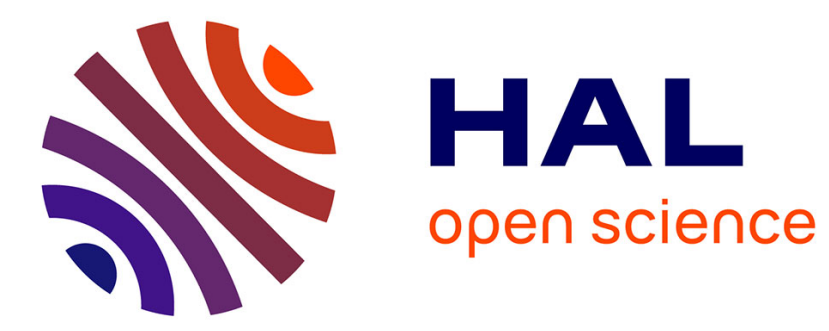

\title{
Impaired antibody response to conjugated meningococcal serogroup $C$ vaccine in asplenic patients
}

\author{
A. Meerveld-Eggink, O. Weerdt, R. M. Voer, G. A. M. Berbers, H. \\ Velzen-Blad, B. J. Vlaminckx, D. H. Biesma, G. T. Rijkers
}

\section{To cite this version:}

A. Meerveld-Eggink, O. Weerdt, R. M. Voer, G. A. M. Berbers, H. Velzen-Blad, et al.. Impaired antibody response to conjugated meningococcal serogroup $\mathrm{C}$ vaccine in asplenic patients. European Journal of Clinical Microbiology and Infectious Diseases, 2010, 30 (5), pp.611-618. 10.1007/s10096010-1129-2 . hal-00654946

\section{HAL Id: hal-00654946 \\ https://hal.science/hal-00654946}

Submitted on 24 Dec 2011

HAL is a multi-disciplinary open access archive for the deposit and dissemination of scientific research documents, whether they are published or not. The documents may come from teaching and research institutions in France or abroad, or from public or private research centers.
L'archive ouverte pluridisciplinaire HAL, est destinée au dépôt et à la diffusion de documents scientifiques de niveau recherche, publiés ou non, émanant des établissements d'enseignement et de recherche français ou étrangers, des laboratoires publics ou privés. 


\section{Impaired antibody response to conjugated meningococcal serogroup C}

vaccine in asplenic patients

Running head: MenC conjugated vaccine in asplenia

Aafke Meerveld-Eggink, ${ }^{1}$ Okke de Weerdt, ${ }^{1}$ Richarda M. de Voer, ${ }^{2}$ Guy A.M. Berbers, ${ }^{2}$

Heleen van Velzen-Blad, ${ }^{3}$ Bart J. Vlaminckx, ${ }^{3}$ Douwe H. Biesma, ${ }^{4}$ Ger T. Rijkers ${ }^{3}$

1. Department of Internal Medicine, St. Antonius Hospital Nieuwegein, the Netherlands

2. Laboratory for Infectious Diseases and Screening, National Institute of Public Health and the Environment, Bilthoven, the Netherlands

3. Department of Medical Microbiology and Immunology, St. Antonius Hospital Nieuwegein, the Netherlands

4. Division of Internal Medicine, University Medical Centre Utrecht, the Netherlands

Word count abstract: 196

Word count text: 2972 


\section{Abstract}

PURPOSE To determine the quantity and quality of antibodies against the meningococcal serogroup $\mathrm{C}(\mathrm{MenC})$ conjugated vaccine in asplenic patients

PATIENTS AND METHODS In 116 asplenic patients, antibody concentrations (lgG) were measured against meningococcal serogroup $\mathrm{C}$ before and after immunisation. Of MenCspecific $\lg G$, both antibody avidity and subclasses of $\lg G 1$ and $\lg G 2$ were determined. RESULTS Mean MenC IgG concentration rose from $0.16 \mu \mathrm{g} / \mathrm{mL}$ prior to vaccination to 3.69 $\mu \mathrm{g} / \mathrm{mL} 3$ weeks post-vaccination, with $67 \%$ of patients reaching the threshold of $\geq 2.0 \mu \mathrm{g} / \mathrm{mL}$. Mean IgG concentration at 35 weeks post-vaccination was $3.10 \mu \mathrm{g} / \mathrm{mL}$. IgG2 concentrations increased more than IgG1. Marginal avidity maturation was seen. Hypo-responders to the first MenC vaccine ( $\mathrm{lgG}$ anti-MenC $\leq 2.0 \mu \mathrm{g} / \mathrm{mL}$ ) were offered a booster dose. After revaccination, 59\% reached the chosen IgG threshold. The IgG concentration rose from 0.29 to $1.12 \mu \mathrm{g} / \mathrm{mL}$, with an increase in the $\lg \mathrm{G} 1 / \mathrm{lgG} 2$ ratio. Avidity indices remained below $33 \%$. CONCLUSIONS In asplenic patients the quantity and quality of antibodies produced after one dose of conjugated MenC vaccination is lower than observed in previous studies in healthy adults. Booster vaccination does lead to a rise in IgG GMC's, but does not lead to higher avidity of antibodies.

Keywords: meningococcal serogroup C, conjugated vaccines, asplenia, avidity, IgG subclasses 


\section{Introduction}

Functional or anatomical asplenic patients are at increased risk of a severe overwhelming post splenectomy infection (OPSI) with encapsulated bacteria. After Streptococcus pneumoniae as the major cause, one of the other prevalent causative organisms is Neisseria meningitidis.[1-3] To reduce the incidence of these infections in asplenic patients, a vaccination schedule including $N$. meningitidis is strongly recommended.[4] Of the known meningococcal groups, 5 groups (A, B, C, Y and $\mathrm{W} 135)$ are responsible for more than $95 \%$ of invasive disease.[5] In 2002, after an outbreak of MenC infection, a national vaccination campaign was performed in the Netherlands in which all persons 1-18 years of age were vaccinated against MenC. Since then, due to vaccination and herd immunity, the circulation of MenC is very low.[6]

Data on the ability of asplenic individuals to establish an adequate antibody response to vaccination with polysaccharide vaccines are conflicting. The response depends among others on the reason for asplenia and on the vaccine that is used (polysaccharide versus conjugated).[7-10] Immunisation with meningococcal polysaccharide vaccines was not recommended for patients with asplenia due to the short duration of protection and the absence of protection against the most common serogroup B.[2,11] With the introduction of conjugated vaccines, inducing long-term immunity, vaccination of asplenic patients with meningococcal conjugated vaccines now is recommended.[11,12]

Beside increase in antibody concentration as a surrogate marker of protection offered by the MenC vaccine, antibody avidity can be determined. Antibody avidity is a biomarker, reflecting the generation of immunological memory after immunisation.[13-15] Antibody avidity is defined as the overall antigen-binding capacity of polyclonal antibodies with different affinities.[13,14,16,17] Polysaccharide conjugate vaccines have the ability to elicit higher avidity antibodies with increased functional activity than do plain polysaccharide 
vaccines.[14] The magnitude of the avidity index is dependent on the type of conjugate vaccine.[18]

In this study, the efficacy of a MenC conjugated vaccine in terms of increase in antibody concentration after vaccination (quantity) and the avidity of the antibodies (quality) is determined in adult, asplenic patients. 


\section{Patients and methods}

\section{$\underline{\text { Patients }}$}

In 2006 and 2007, patients were included in a study to evaluate the vaccination coverage of adult asplenic patients in the Utrecht area of the Netherlands.[19] This study was approved by the local institutional ethics committee and all patients gave written informed consent. When applicable, patients were vaccinated with conjugated pneumococcal, Hib and meningococcal vaccines according to the institutions protocol and serum samples were taken pre- and post-vaccination to determine antibody concentrations. Results of the pneumococcal and Hib vaccines will be reported separately (Meerveld et al., manuscript submitted).

\section{$\underline{\text { Vaccination protocol }}$}

Patients were vaccinated against $N$. meningitidis when they were never vaccinated before, when vaccination status against the meningococcus could not be retrieved or when vaccination with a polysaccharide meningococcal vaccine occurred more than three years ago. A first dose of conjugate meningococcal group $\mathrm{C}$ vaccine was given, consisting of MenC polysaccharide covalently coupled to tetanus toxoid (NeisVac-C ${ }^{\circledR}$, Baxter AG, Vienna, Austria). Blood samples were drawn pre-immunization, 3 weeks and 35 weeks postimmunization. Serum samples were stored at $-20^{\circ} \mathrm{C}$ until use. When antibody concentrations after the first vaccination remained below $2 \mu \mathrm{g} \mathrm{lgG} / \mathrm{mL}$ in patients (so-called hyporesponders), a second dose of conjugate MenC vaccine was given.

\section{$\underline{\text { Laboratory determinations }}$}

Meningococcal antibody concentrations were measured against serotype $\mathrm{C}$ by multiplex immunoassay (MIA) as described previously.[20-22] All antibody concentrations were logtransformed and geometric mean concentrations (GMC) were calculated. Seroconversion was defined as $a \geq$ fourfold increase in antibody concentration after vaccination. The chosen 
anti-meningococcal antibody threshold for correlation with long-term protection was $\geq 2.0$ $\mu \mathrm{g} / \mathrm{mL}$.

MenC-specific IgG1 and IgG2 subclasses were measured by a modification of the MIA as described above.[23] Previously assigned concentrations of meningococcal IgG1, and IgG2 antibodies were used in this assay.[24,25]

Avidity of MenC-specific IgG antibodies was assessed by using a modification of the MIA for determining MenC-specific IgG.[20,21] Serum samples with an IgG concentration of $\geq 0.25$ $\mu \mathrm{g} / \mathrm{mL}$ were diluted to an antibody concentration of $25 \mathrm{ng} / \mathrm{mL}$ in a buffer composed of $25 \%$ antibody depleted human serum (Valley Biomedical, USA). Ammonium thiocyanate $\left(\mathrm{NH}_{4} \mathrm{SCN}\right.$; Sigma-Aldrich, St. Louis, $\left.\mathrm{MO}\right)$ was added to a final concentration of $0.5 \mathrm{M}$ in order to dissociate low-avidity antigen-antibody binding.[26] After incubation of polysaccharideconjugated-beads with serum, $0.5 \mathrm{M} \mathrm{NH}_{4} \mathrm{SCN}$ was added for 10 minutes exactly. Beads were washed, $R$-phycoerythrin(RPE)-conjugated goat anti-human IgG (gamma chain specific) (Jackson ImmunoResearch Laboratories Inc., West Grove, PA) was added and incubated for a further 30 minutes. After a final wash, the plate was read on a Luminex-100 system (Bioplex; Bio-Rad Laboratories, Hercules, CA). Data are expressed as the avidity index (AI) which is the percentage of antibodies that remained bound to the MenC polysaccharideconjugated beads after treatment with $\mathrm{NH}_{4} \mathrm{SCN}$ and was calculated as follows: $\mathrm{Al}=$ (amount of $\operatorname{lgG}$ bound in the presence of $0.5 \mathrm{M} \mathrm{NH}_{4} \mathrm{SCN}$ )/ (amount of $\operatorname{lgG}$ bound in PBS) $x$ 100. Sera were categorized into high, intermediate and low avidity, based on the Al: high, 100-67\%; medium, 66-34\%; and low, 0-33\%.

\section{Statistical analysis}

Comparisons of GMC before and after vaccination (paired samples) and comparisons of antibody avidity before and after vaccination were performed using the paired samples Ttest. Independent sample T-test and Chi-square were used when appropriate. A p-value of $\leq$ 
0.05 was considered statistically significant. In case of subset analysis, in small groups the Wilcoxon signed rank test was used.

For statistical analysis, the Statistical Package for the Social Sciences (SPSS) for Windows ${ }^{\circledR}$ software, version 15.0 (SPSS Inc., Chicago, IL) was used. 


\section{Results}

We included 184 asplenic patients in this study. Previously, we have described the characteristics of the majority of this group.[19] In 117 patients a MenC conjugated vaccine was indicated. Samples after vaccination, of all but one patient, were available and these 116 sera were analysed in this study. Baseline characteristics of the patients are given in Table 1. All but one patient underwent a splenectomy, the prevalent reason being a trauma $(30 \%)$. One patient was considered to be functional asplenic, because of irradiation of the spleen for Hodgkin's disease.

Seventeen (15\%) patients had previously received a meningococcal vaccination, either MenA,-C,-W135 and-Y polysaccharide vaccine $(n=6)$, MenA,-C polysaccharide vaccine $(n=4)$ or an otherwise not-specified meningococcal vaccine $(n=7)$. The median time since the last vaccination was 4 years (range 2-6 years).

\section{Meningococcal antibody concentrations}

In asplenic patients, MenC geometric mean antibody concentrations (GMC) rose from 0.16 $\mu \mathrm{g} / \mathrm{mL}$ prior to vaccination to $3.69 \mu \mathrm{g} / \mathrm{mL}$ three weeks post-vaccination (Figure 1). For MenC, trauma patients had significantly higher post-vaccination antibody concentrations than the other asplenic patients $(p<0.05)$. We observed no statistically significant influence of age at splenectomy, age at vaccination or time from splenectomy to vaccination on the antibody concentrations of MenC-specific lgG. Previous meningococcal vaccination had a statistically significant influence on the MenC GMC's pre- and post-vaccination $(p<0.05)$. GMC prevaccination in previously vaccinated patients was $1.6 \mu \mathrm{g} / \mathrm{mL}(95 \% \mathrm{Cl} 0.5-5.7)$ versus 0.1 $\mu \mathrm{g} / \mathrm{mL}(95 \% \mathrm{Cl} 0.1-0.2)$ in patients not vaccinated before. For GMC post-vaccination, these data were $10.7 \mu \mathrm{g} / \mathrm{mL}(95 \% \mathrm{Cl} 4.8-24.0)$ and $3.1 \mu \mathrm{g} / \mathrm{mL}$ (95\% Cl 2.1-4.8), respectively. GMC's post-vaccination were $10 \%$ higher in patients receiving the MenC vaccine alone 
compared to patients receiving concomitant pneumococcal and/or Hib vaccines. This difference was not statistically significant.

Post-vaccination, $67 \%$ of the patients reached the threshold of $2.0 \mu \mathrm{g} / \mathrm{mL}$ for MenC (Table 2). Patients who were splenectomised because of trauma reached this threshold more often than other patients $(p<0.05)$. Time since splenectomy did not influence seroconversion of MenC.

In 38 patients, we were able to determine meningococcal antibody concentrations up to approximately eight months after the first conjugate MenC vaccine. Mean time since vaccination was 8.3 months (range 6,5-10,5). GMC's for serogroup C are given in Figure 2. In this group of 38 patients, for MenC GMC pre-vaccination was $0.21 \mu \mathrm{g} / \mathrm{mL}$ and rose to $3.71 \mu \mathrm{g} / \mathrm{mL}$ post-vaccination ( $\mathrm{p}<0.05$ ). After eight months, a decrease in $\mathrm{GMC}$ to $3.10 \mu \mathrm{g} / \mathrm{mL}$ was observed. This decrease was not significant compared to the GMC 3 weeks postvaccination.

Thirty eight patients (33\%) did not reach adequate antibody concentrations after one dose of conjugate vaccine. Characteristics of this group of hypo-responders are given in Table 3. These hypo-responders had an adequate response to Hib vaccination ( $98 \%$ reached the threshold) and pneumococcal conjugate vaccination (93,5\% reached protective antibody concentrations of $1.0 \mu \mathrm{g} / \mathrm{mL}$ for 5 out of 7 vaccine-serotypes after one vaccination). Of the 38 patients, $58 \%(n=22)$ did reach seroconversion for serogroup $C$ after the first vaccinaton. Because of their subnormal antibody response, a revaccination with the MenC conjugate vaccine was performed. Sera after revaccination were available of 22 patients. In this patient group, GMC pre-vaccination was $0.05 \mu \mathrm{g} / \mathrm{mL}$, rising after the first vaccination to $0.29 \mu \mathrm{g} / \mathrm{mL}$. After the second vaccination, the GMC of MenC PS-specific IgG rose significantly to 1.12 $\mu \mathrm{g} / \mathrm{mL}$ (Figure 3). Thirteen (59\%) patients reached the threshold of $\geq 2.0 \mu \mathrm{g} / \mathrm{mL}$. 


\section{Antibody avidity}

The avidity index (Al) of the MenC antibodies was measured using a grading system to discriminate between sera with low $\mathrm{Al}$ (0-33\%), intermediate $\mathrm{Al}(34-66 \%)$ and high $\mathrm{Al}$ (67$100 \%$ ). Only sera that $\geq 0.25 \mu \mathrm{g} / \mathrm{mL}$ of MenC-specific lgG were selected for Al determination. In the overall cohort, the geometric mean Al (GMAl) was 27\% (95\% Cl 19-35\%) prevaccination $(n=48), 25 \%(95 \%$ Cl $20-30 \%) 3$ weeks post-vaccination $(n=104)$ and $32 \%(95 \%$ CI $23-41 \%) 35$ weeks post-vaccination ( $n=34)$, respectively. In patients who were revaccinated, the mean $\mathrm{Al}$ rose from $14 \%$ after the first dose of vaccine to $26 \%$ after the second vaccination $(n=13 ; p<0.01)$. No associations were found between the Al pre- and post-vaccination and the underlying disease resulting in asplenia or previous vaccination with meningococcal vaccines.

\section{IgG subclasses}

In Figure 4a, the concentrations of MenC IgG1 and IgG2 are given before, three weeks and 35 weeks after vaccination in patients with $\geq 0.25 \mu \mathrm{g} / \mathrm{mL}$ of MenC PS-specific IgG prevaccination. In Figure $4 \mathrm{~b}$ the development of the $\lg \mathrm{G} 1 / \lg \mathrm{g} 2$ ratio in this patient group is given in relation to the changes in avidity indices. Great inter-individual differences between antibody responses were seen, with lgG1/lgG2 ratio's increasing in 7 patients and decreasing in 26 patients. In only 7 patients the $\lg$ G1/lgG2 ratio after one conjugated vaccination was $>1$ and in only 2 patients the ratio changed from $<1$ to $>1$ post-vaccination. The mean IgG1 concentration after vaccination was $1.17 \mu \mathrm{g} / \mathrm{mL}$ versus $9.52 \mu \mathrm{g} / \mathrm{mL} \operatorname{lgG} 2$. The ratio of $\lg G 1 / \lg G 2$ did not change by vaccination ( 0.23 pre-vaccination, 0.253 weeks post-vaccination, and 0.2035 weeks post-vaccination).

After revaccination, the mean $\lg \mathrm{G} 1$ concentration rose from 0.93 to $3.25 \mu \mathrm{g} / \mathrm{mL}$ (Figure 4c). The concentration of $\lg G 2$ rose from 0.76 to 1.72 . The ratio of $\lg \mathrm{G} 1 / \lg G 2$ was 1.43 postvaccination, which is significantly higher $(p<0.01)$ than after primary vaccination. 


\section{Discussion}

The immune response to the MenC conjugate vaccine in a group of 116 asplenic patients was found to be of poor quality and quantity. After a single dose of MenC conjugate vaccine, only $67 \%$ of the asplenic patients reached the chosen threshold antibody concentration of $\geq$ $2.0 \mu \mathrm{g} / \mathrm{mL}$, with an increase in GMC from $0.16 \mu \mathrm{g} / \mathrm{mL}$ to $3.69 \mu \mathrm{g} / \mathrm{mL}$ post-vaccination. In healthy children and adults, including our own series, 5-10 times higher GMC's were reached after one dose of this MenC conjugate vaccine. [27-30] Previously, Balmer et al., using a different MenC conjugated vaccine, found three times higher GMC's in asplenic patients after vaccination compared to our asplenic patients.[31] In that study, no difference was found between IgG GMC's in asplenic patients and an age-matched control group. However, functionality of the antibodies (based on bactericidal antibody in serum (SBA)) was significantly lower in the asplenic patient group. In our asplenic patient group, the functionality of the antibodies in terms of antibody avidity was also low. As indicated above we used a different MenC conjugated vaccine (MenC coupled to tetanus toxoid (TT)) than Balmer et al. $\left(\mathrm{CRM}_{197}\right.$ conjugated). The vaccine we used has turned out to be more immunogenic in healthy subjects than other MenC conjugated vaccines. [30] Yet, in our patients lower antibody concentrations were observed than in the study of Balmer et al.[31] Balmer et al. recommend a second dose of vaccine offered to the patients if their postvaccination concentration is below the proposed protective threshold, or routinely offering two doses of MenC conjugate vaccine. In our study, after revaccination still $41 \%$ of the revaccinated patients did not achieve protective serum levels. This percentage is in accordance with the percentage of hypo-responders found by Balmer et al.[31] We therefore can conclude that hypo-responsiveness to MenC remained in a considerable fraction of patients and cannot be overcome by a more potent conjugate MenC vaccine.

In healthy adults, IgG GMC's fell by $50 \%$ from 33.3 to $16.7 \mathrm{ug} / \mathrm{mL}$ at six months after a single dose of MenC-TT vaccine.[29] In the asplenic patients of whom sera were available eight 
months after vaccination, GMC dropped only slightly from 3.69 to $3.10 \mu \mathrm{g} / \mathrm{mL}$. The asplenic state of the patients may be a factor which determines the only marginal decrease in GMC in the 8 months post-vaccination. In accordance with our findings, in the study of Smets et al., 6 months after pneumococcal conjugate vaccination in asplenic children, GMC's had not decreased significantly.[10] High antibody concentrations months after vaccination can be explained by ongoing production of antibodies and/or lower rate of removal from the circulation. In asplenic individuals, alternative homing of peripheral B-cells takes place, with B-memory-cells homing in peripheral organs and bone marrow in stead of in the spleen. These specific niches may be favourable for long lived plasma cells. Another argument for longer persistence of antibodies in asplenic patients is the absence of the reticulo-endothelial system (RES) function of the spleen. Immune complexes can longer remain in circulation and cause prolonged B-lymphocyte activation.

Antibody persistence following pneumococcal polysaccharide or conjugate vaccination of healthy adults (50-80 years) with an intact spleen has been studied by Goldblatt et al.[32] One year after one dose of pneumococcal conjugate vaccine, GMC's for 4 out of the 7 pneumococcal serotypes were at least $80 \%$ of the GMC's at the peak of the response, i.e. 1 month after vaccination. It should therefore be concluded that polysaccharide (conjugated) vaccines have the ability to induce antibody levels which persist for periods up to 1 year after vaccination, in the presence or absence of a functional spleen.

\section{Avidity and IgG subclasses}

It is thought that long term protection after immunisation with conjugate vaccines depends on herd immunity, persistence of anti-capsular antibodies in serum and immunological memory.[33] As a marker of immunological memory, avidity of the MenC-specific antibodies was determined.

High antibody avidity indicates high functional activity of the meningococcal antibodies.[13] In the asplenic patient group, the GMAI rose from $19 \% 3$ weeks post-vaccination to $29 \%$ eight months after vaccination. The rise in antibody avidity is consistent with earlier studies 
on affinity maturation of antibodies after conjugated vaccines.[13,15,29,34] However, in our study, most patients do not develop antibodies with intermediate or high avidity; most antibodies are of low avidity.

In adults, natural exposure to meningococci and exposure to cross-reactive agents can lead to the development of memory B-cells (priming). These memory B-cells will be stimulated after polysaccharide and conjugate vaccination, leading to higher avidity indices in adults compared to children.[17,35] For this reason, measurement of Al's in adults may be considered to be of less importance.[17,35,36] In our adult asplenic group however, most adults had low antibody avidity indices before vaccination. In this patient group therefore, an antibody Al measurement may be an adequate way of determining the development of immunological memory.

In general, IgG1 antibodies have a higher affinity than IgG2.[34] The ability to induce a IgG1 T-cell dependent (TD) response is among others dependent on age at vaccination, type of vaccine and type of adjuvant.[36-38] In the asplenic patients studied, after one meningococcal conjugate vaccination, both $\lg G 1$ and $\lg G 2$ increase, with higher concentrations of $\lg \mathrm{G} 2$ (mean concentration $9.52 \mu \mathrm{g} / \mathrm{mL} 3$ weeks after vaccination) than $\lg \mathrm{G} 1$ (mean concentration $1.17 \mu \mathrm{g} / \mathrm{mL}$ ). There is a large variability in the $\lg \mathrm{G} 1 / \lg \mathrm{G} 2$ ratio in individual patients. This is consistent with the findings of Findlow et al., who detected significant increases in IgG1 and IgG2 with large differences in lgG1/lgG2 ratio's after vaccination with one dose of quadrivalent meningococcal conjugated vaccine in healthy adults.[37] After revaccination, the amount of $\lg G 1$ in the asplenic population rises more than IgG2, suggesting that after revaccination, the T-cell dependent response is more adequate.

\section{Influence of immunisation schedule}

In contrast with the study of Balmer et al., in the current study a number of patients received Hib and pneumococcal vaccines concomitant with the MenC vaccine, dependent on the 
vaccination status before start of the study.[31] The response to Hib vaccine was much better than to MenC vaccine; $97 \%$ of the patients reached a protective antibody concentration after vaccination (Meerveld-Eggink, manuscript submitted). Theoretically, the diminished response to MenC could be due to the simultaneous administration of different vaccines, thereby overloading the immune system. Although the MenC-specific IgG GMC post-vaccination in patients receiving concomitant vaccines was $10 \%$ lower than in patients solely immunised with the MenC vaccine, this difference was not statistically significant.

In both the current study in asplenic patients and the study of Balmer et al., 15-30\% of patients had received prior MenC polysaccharide vaccination. [31] These previously vaccinated patients had higher MenC GMC's pre-vaccination than patients not vaccinated with meningococcal vaccines before. In contrast to Balmer et al., we found that previous MenC vaccination also lead to higher GMC's post-vaccination.

\section{Conclusions}

We conclude that a single dose of MenC conjugated vaccine does not result in an adequate antibody response in $33 \%$ of asplenic patients. A second dose of MenC vaccine leads to an additional increase in antibody concentration and avidity, suggesting that asplenic patients benefit from a second dose of vaccine. This conclusion should be limited to older, asplenic patients, who did not receive MenC conjugated vaccines as part of the Dutch National Vaccination Programme. The relevance of a second dose of vaccine in countries where all children are vaccinated against MenC and circulation of MenC therefore is low, should be considered. 


\section{Acknowledgements}

The authors thank Mrs. A van Heugten-Roeling (Department of Medical Microbiology and Immunology of the St. Antonius Hospital Nieuwegein) for her contribution to this study.

\section{Conflict of interest}

The authors declare that they have no conflict of interest. 


\section{References}

[1] Prevention of pneumococcal disease: recommendations of the Advisory Committee on Immunization Practices (ACIP). MMWR Recomm Rep 1997;46(RR-8):1-24.

[2] Guidelines for the prevention and treatment of infection in patients with an absent or dysfunctional spleen. Working Party of the British Committee for Standards in Haematology Clinical Haematology Task Force. BMJ 1996;312(7028):430-4.

[3] Davies JM, Barnes R, Milligan D, British Committee for Standards in Haematology. Working Party of the Haematology/Oncology Task Force. Update of guidelines for the prevention and treatment of infection in patients with an absent or dysfunctional spleen. Clin Med 2002;2(5):440-3.

[4] Bilukha OO, Rosenstein N, National Center for Infectious Diseases, Centers for Disease Control and Prevention (CDC). Prevention and control of meningococcal disease.

Recommendations of the Advisory Committee on Immunization Practices (ACIP). MMWR Recomm Rep 2005;54(RR-7):1-21.

[5] Granoff DM, Harris SL. Protective activity of group C anticapsular antibodies elicited in two-year-olds by an investigational quadrivalent Neisseria meningitidis-diphtheria toxoid conjugate vaccine. Pediatr Infect Dis J 2004;23(6):490-7.

[6] de Greeff SC, de Melker HE, Spanjaard L, Schouls LM, van Derende A. Protection from routine vaccination at the age of 14 months with meningococcal serogroup $C$ conjugate vaccine in the Netherlands. Pediatr Infect Dis J 2006;25(1):79-80.

[7] Giebink GS, Foker JE, Kim Y, Schiffman G. Serum antibody and opsonic responses to vaccination with pneumococcal capsular polysaccharide in normal and splenectomized children. J Infect Dis 1980;141(3):404-12.

[8] Sullivan JL, Ochs HD, Schiffman G, Hammerschlag MR, Miser J, Vichinsky E et al. Immune response after splenectomy. Lancet 1978;1(8057):178-81.

[9] Eigenberger K, Sillaber C, Greitbauer M, Herkner H, Wolf H, Graninger W et al. Antibody responses to pneumococcal and hemophilus vaccinations in splenectomized patients with hematological malignancies or trauma. Wien Klin Wochenschr 2007;119(7-8):228-34. 
[10] Smets F, Bourgois A, Vermylen C, Brichard B, Slacmuylders P, Leyman S et al. Randomised revaccination with pneumococcal polysaccharide or conjugate vaccine in asplenic children previously vaccinated with polysaccharide vaccine. Vaccine $2007 ; 25(29): 5278-82$.

[11] Melles DC, de Marie S. Prevention of infections in hyposplenic and asplenic patients: an update. Neth J Med 2004;62(2):45-52.

[12] Davidson RN, Wall RA. Prevention and management of infections in patients without a spleen. Clin Microbiol Infect 2001;7(12):657-60.

[13] Wuorimaa T, Dagan R, Vakevainen M, Bailleux F, Haikala R, Yaich M et al. Avidity and subclasses of $\lg G$ after immunization of infants with an 11-valent pneumococcal conjugate vaccine with or without aluminum adjuvant. J Infect Dis 2001;184(9):1211-5.

[14] Harris SL, Tsao H, Ashton L, Goldblatt D, Fernsten P. Avidity of the immunoglobulin G response to a Neisseria meningitidis group C polysaccharide conjugate vaccine as measured by inhibition and chaotropic enzyme-linked immunosorbent assays. Clin Vaccine Immunol 2007;14(4):397-403.

[15] Goldblatt D, Vaz AR, Miller E. Antibody avidity as a surrogate marker of successful priming by Haemophilus influenzae type b conjugate vaccines following infant immunization. J Infect Dis 1998;177(4):1112-5.

[16] Kelly DF, Pollard AJ, Moxon ER. Immunological memory: the role of B cells in long-term protection against invasive bacterial pathogens. JAMA 2005;294(23):3019-23.

[17] Balmer P, Borrow R. Serologic correlates of protection for evaluating the response to meningococcal vaccines. Expert Rev Vaccines 2004;3(1):77-87.

[18] Schlesinger Y, Granoff DM. Avidity and bactericidal activity of antibody elicited by different Haemophilus influenzae type b conjugate vaccines. The Vaccine Study Group. JAMA 1992;267(11):1489-94.

[19] Meerveld-Eggink A, de Weerdt O, Rijkers GT, van Velzen-Blad H, Biesma DH. Vaccination coverage and awareness of infectious risks in patients with an absent or dysfunctional spleen in the Netherlands. Vaccine 2008;26(52):6975-9. 
[20] de Voer RM, Schepp RM, Versteegh FG, van der Klis FR, Berbers GA. Simultaneous detection of Haemophilus influenzae type b polysaccharide-specific antibodies and Neisseria meningitidis serogroup $\mathrm{A}, \mathrm{C}, \mathrm{Y}$, and $\mathrm{W}-135$ polysaccharide-specific antibodies in a fluorescent-bead-based multiplex immunoassay. Clin Vaccine Immunol 2009;16(3):433-6. [21] de Voer RM, van der Klis FR, Engels CW, Schepp RM, van de Kassteele J, Sanders EA et al. Kinetics of antibody responses after primary immunization with meningococcal serogroup $\mathrm{C}$ conjugate vaccine or secondary immunization with either conjugate or polysaccharide vaccine in adults. Vaccine 2009;27(50):6974-82.

[22] Lal G, Balmer P, Joseph H, Dawson M, Borrow R. Development and evaluation of a tetraplex flow cytometric assay for quantitation of serum antibodies to Neisseria meningitidis serogroups A, C, Y, and W-135. Clin Diagn Lab Immunol 2004;11(2):272-9. [23] de Voer RM, van der Klis FR, Engels CW, Rijkers GT, Sanders EA, Berbers GA. Development of a fluorescent-bead-based multiplex immunoassay to determine immunoglobulin $G$ subclass responses to Neisseria meningitidis serogroup A and $C$ polysaccharides. Clin Vaccine Immunol 2008;15(8):1188-93.

[24] Holder PK, Maslanka SE, Pais LB, Dykes J, Plikaytis BD, Carlone GM. Assignment of Neisseria meningitidis serogroup A and C class-specific anticapsular antibody concentrations to the new standard reference serum CDC1992. Clin Diagn Lab Immunol 1995;2(2):132-7. [25] Joseph H, Balmer P, Bybel M, Papa T, Ryall R, Borrow R. Assignment of Neisseria meningitidis serogroups $A, C, W 135$, and $Y$ anticapsular total immunoglobulin $G$ (lgG), $\lg G 1$, and IgG2 concentrations to reference sera. Clin Diagn Lab Immunol 2004;11(1):1-5. [26] Anttila M, Eskola J, Ahman H, Kayhty H. Avidity of IgG for Streptococcus pneumoniae type $6 \mathrm{~B}$ and $23 \mathrm{~F}$ polysaccharides in infants primed with pneumococcal conjugates and boosted with polysaccharide or conjugate vaccines. J Infect Dis 1998;177(6):1614-21. [27] Zonneveld-Huijssoon E, Ronaghy A, Van Rossum MA, Rijkers GT, van der Klis FR, Sanders EA et al. Safety and efficacy of meningococcal c vaccination in juvenile idiopathic arthritis. Arthritis Rheum 2007;56(2):639-46. 
[28] Burrage M, Robinson A, Borrow R, Andrews N, Southern J, Findlow J et al. Effect of vaccination with carrier protein on response to meningococcal $\mathrm{C}$ conjugate vaccines and value of different immunoassays as predictors of protection. Infect Immun 2002;70(9):494654.

[29] Richmond P, Goldblatt D, Fusco PC, Fusco JD, Heron I, Clark S et al. Safety and immunogenicity of a new Neisseria meningitidis serogroup C-tetanus toxoid conjugate vaccine in healthy adults. Vaccine 1999;18(7-8):641-6.

[30] Richmond P, Borrow R, Goldblatt D, Findlow J, Martin S, Morris R et al. Ability of 3 different meningococcal $\mathrm{C}$ conjugate vaccines to induce immunologic memory after a single dose in UK toddlers. J Infect Dis 2001;183(1):160-3.

[31] Balmer P, Falconer M, McDonald P, Andrews N, Fuller E, Riley C et al. Immune response to meningococcal serogroup $\mathrm{C}$ conjugate vaccine in asplenic individuals. Infect Immun 2004;72(1):332-7.

[32] Goldblatt D, Southern J, Andrews N, Ashton L, Burbidge P, Woodgate S et al. The immunogenicity of 7-valent pneumococcal conjugate vaccine versus 23 -valent polysaccharide vaccine in adults aged 50-80 years. Clin Infect Dis 2009;49(9):1318-25. [33] Blanchard Rohner G, Snape MD, Kelly DF, John T, Morant A, Yu LM et al. The magnitude of the antibody and memory $B$ cell responses during priming with a proteinpolysaccharide conjugate vaccine in human infants is associated with the persistence of antibody and the intensity of booster response. J Immunol 2008;180(4):2165-73.

[34] Southern J, Deane S, Ashton L, Borrow R, Goldblatt D, Andrews N et al. Effects of prior polysaccharide vaccination on magnitude, duration, and quality of immune responses to and safety profile of a meningococcal serogroup $C$ tetanus toxoid conjugate vaccination in adults. Clin Diagn Lab Immunol 2004;11(6):1100-4.

[35] Goldblatt D, Borrow R, Miller E. Natural and vaccine-induced immunity and immunologic memory to Neisseria meningitidis serogroup C in young adults. J Infect Dis 2002;185(3):397400. 
[36] Hutchins WA, Carlone GM, Westerink MA. Elderly immune response to a TI-2 antigen: heavy and light chain use and bactericidal activity to Neisseria meningitidis serogroup $C$ polysaccharide. J Infect Dis 1999;179(6):1433-40.

[37] Findlow H, Southern J, Mabey L, Balmer P, Heyderman RS, Auckland C et al. Immunoglobulin G subclass response to a meningococcal quadrivalent polysaccharidediphtheria toxoid conjugate vaccine. Clin Vaccine Immunol 2006;13(4):507-10.

[38] Makela O, Mattila P, Rautonen N, Seppala I, Eskola J, Kayhty H. Isotype concentrations of human antibodies to Haemophilus influenzae type b polysaccharide (Hib) in young adults immunized with the polysaccharide as such or conjugated to a protein (diphtheria toxoid). J Immunol 1987;139(6):1999-2004. 
Table 1. Baseline characteristics of asplenic patients vaccinated with MenC conjugate vaccine

Patients (n) 116

Male gender $59(51)$

Reason for Sx

Trauma $35(30)$

ITP $18(16)$

Hodgkin's disease $16(14)$

Spherocytosis $16(14)$

Other reasons $30(26)$

Functional asplenia $1(1)$

Age at Sx in years $28.3(3-78)$

Age at vaccination in years $52.5(23-86)$

Time from Sx to vaccination in years $24(0-55)$

ITP= Idiopathic thrombocytopenic purpura

Sx= splenectomy

For gender and reason for asplenia, data are given in numbers of patients with percentages recorded in parentheses. For age at Sx, age at vaccination and time from Sx to vaccination, data are given in median number of years, with the range in parentheses 
Table 2. Neisseria meningitidis serogroup C: response to vaccination

\begin{tabular}{ll}
$\geq 2.0 \mu \mathrm{g} \mathrm{IgG} / \mathrm{mL}$ pre-vaccination: $\mathrm{n}(\%)$ & $14(12)$ \\
$\geq 2.0 \mu \mathrm{g} \mathrm{IgG} / \mathrm{mL}$ post-vaccination: $\mathrm{n}(\%)$ & $78(67)$ \\
Seroconversion: $\mathrm{n}(\%)$ & $93(80)$ \\
\hline
\end{tabular}

Data are given in numbers of patients with percentages in parentheses

Seroconversion: $a \geq$ fourfold increase in antibody concentration after vaccination 
Table 3. Characteristics of responders and hypo-responders to one dose of MenC conjugated vaccine

\begin{tabular}{lll}
\hline & responders & hypo-responders \\
\hline Patients $(\mathrm{n})$ & 78 & 38 \\
Male gender & $39(50)$ & $20(53)$ \\
Reason for Sx & & \\
$\quad$ Trauma & $31(40)$ & $4(11)$ \\
$\quad$ Haematological malignancy & $12(15)$ & $6(16)$ \\
$\quad 35(45)$ & $28(74)$ \\
Other reasons & $27(5-76)$ & $30(3-78)$ \\
Age at Sx in years & $52.0(23-86)$ & $53.5(29-83)$ \\
Age at vaccination in years & $25(0-55)$ & $23(2-50)$ \\
Time from Sx to vaccination in years & $14(18)$ & $3(8)$ \\
Previously vaccinated &
\end{tabular}

$\mathrm{Sx}=$ splenectomy

Hypo-responder $=$ MenC-specific $\lg G<2.0 \mu \mathrm{g} \lg \mathrm{G} / \mathrm{mL}$ post-vaccination

For gender, reason for Sx and previously vaccinated, data are given in numbers of patients with percentages recorded in parentheses. For age at $\mathrm{Sx}$, age at vaccination and time from Sx to vaccination, data are given in mean number of years, with the range in parentheses 
Figure 1. Geometric mean concentrations of MenC IgG before and after MenC conjugate vaccination in asplenic patients $(n=116)$

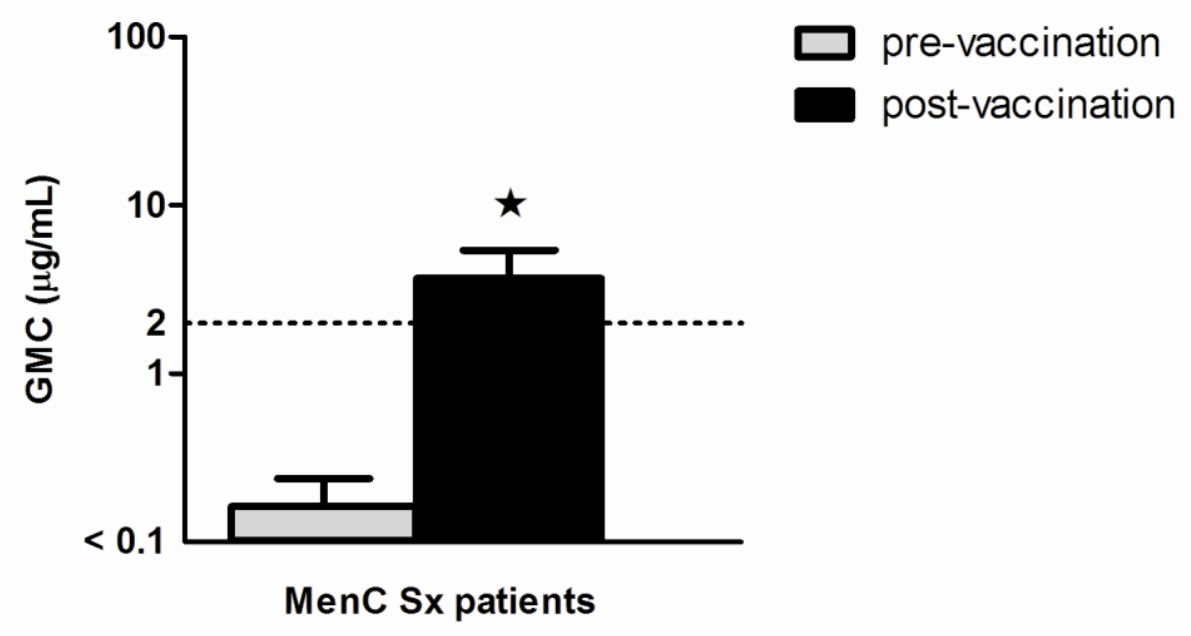

$\mathrm{GMC}=$ geometric mean concentration

Sx $=$ splenectomy

$\star$ statistically significant increase $(p<0.05)$ in antibody concentration post-vaccination compared to pre-vaccination 
Figure 2. Geometric mean concentrations eight months after vaccination

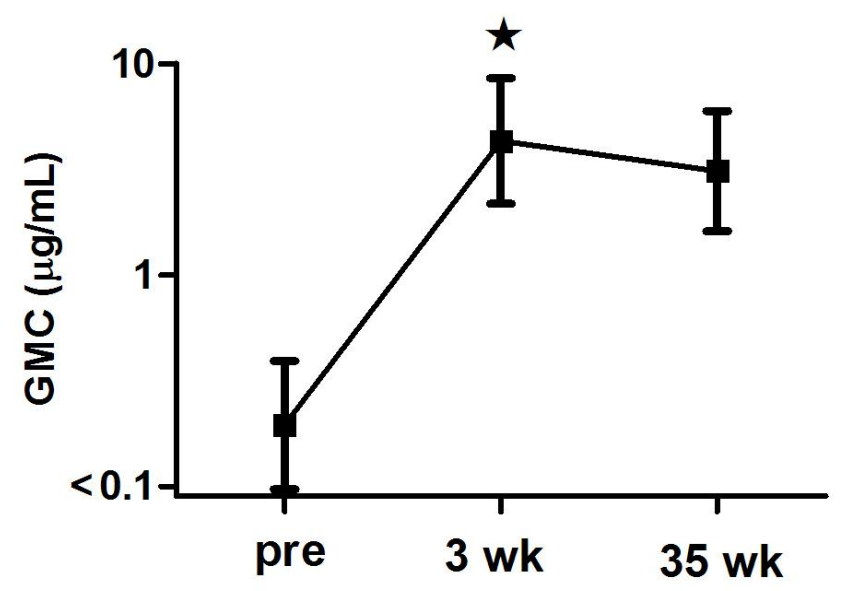

Time since vaccination

GMC: Geometric mean concentration in $\mu \mathrm{g} / \mathrm{mL}$ with $95 \%$ confidence interval

$\star$ statistically significant increase $(p<0.05)$ in antibody concentration post-vaccination compared to pre-vaccination 
Figure 3. Geometric mean concentrations after MenC revaccination $(n=22)$
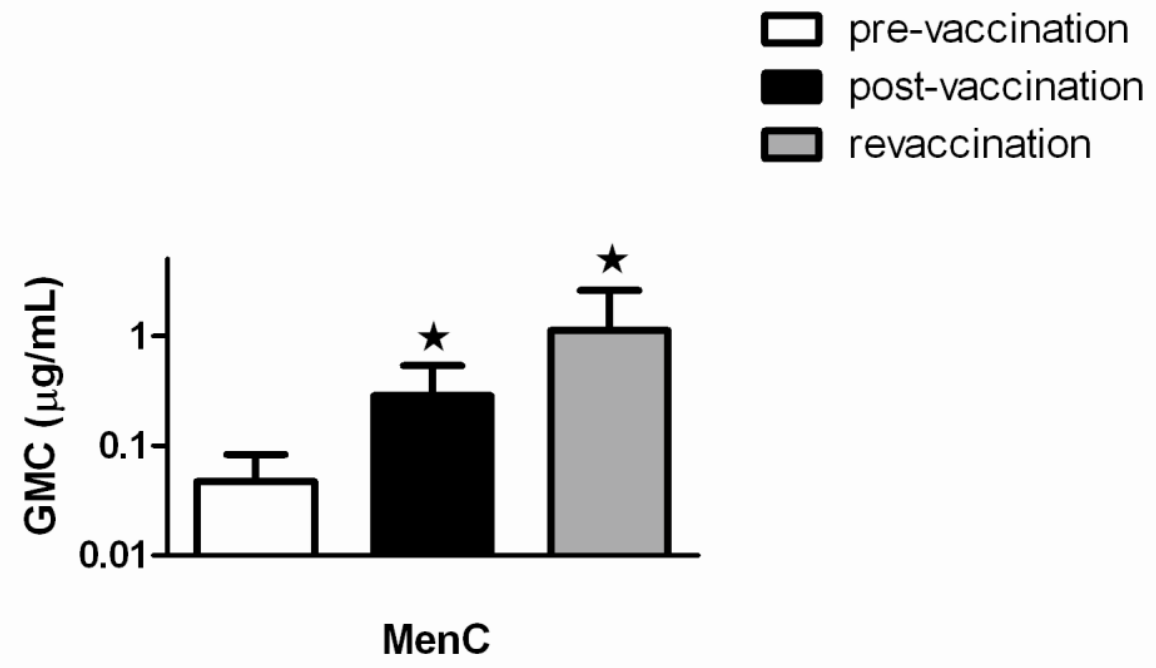

GMC: Geometric mean concentration in $\mu \mathrm{g} / \mathrm{mL}$ with upper $95 \%$ confidence interval $\star$ statistically significant increase $(p<0.05)$ in antibody concentration post-vaccination compared to pre-vaccination 
Figure 4a. Concentrations of MenC $\lg G 1$ and $\lg G 2$ in relation to time after vaccination

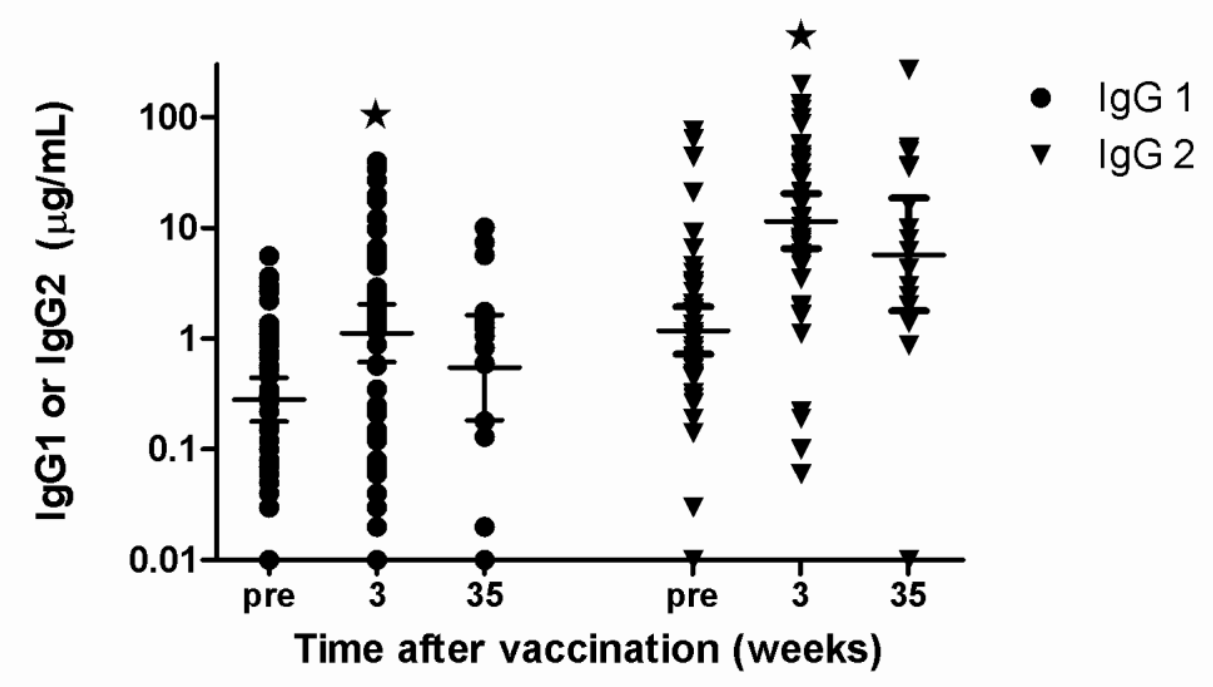

$\lg \mathrm{G}$ with lines at mean with 95\% confidence interval

$\star \mathrm{p}<0.05$

Figure 4b. Development of MenC IgG1/lgG2 ratio compared to changes in avidity

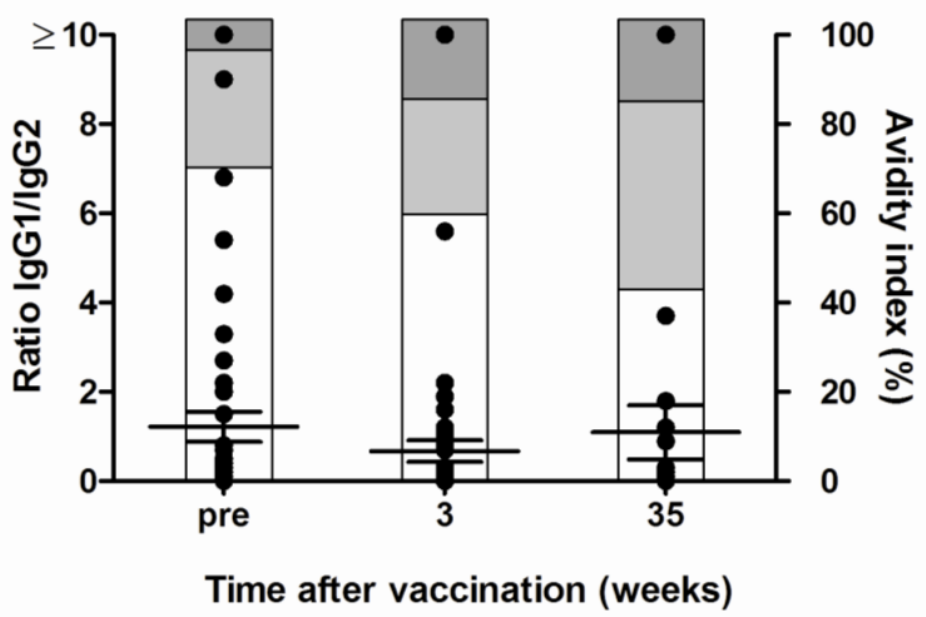

Dots: IgG with lines at mean with SEM

Columns: Avidity indices: dark gray $67-100 \%$, light gray $34-66 \%$, white $0-33 \%$ 
Figure 4c. Concentrations of MenC $\lg G 1$ and $\lg G 2$ after the first and second conjugate vaccine in hypo-responders

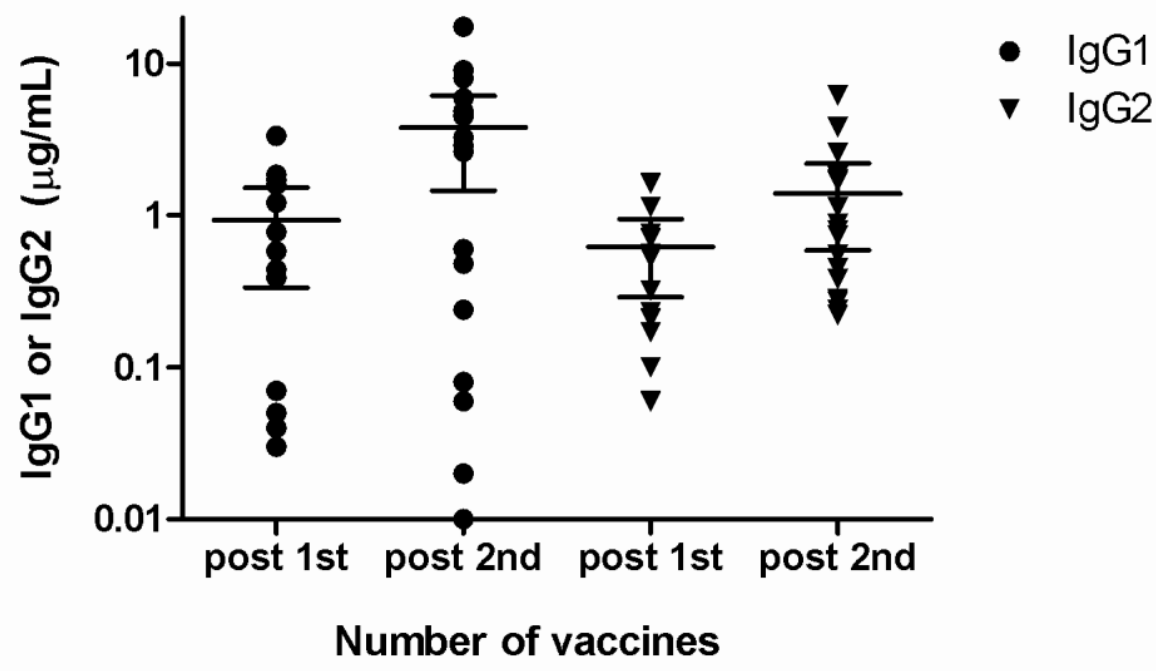

IgG with lines at mean with $95 \%$ confidence interval 